\title{
Developing Healthy Food Preferences in Preschool Children Through Taste Exposure, Sensory Learning, and Nutrition Education
}

\author{
Chandani Nekitsing $^{1} \cdot$ Marion M. Hetherington ${ }^{1} \cdot$ Pam Blundell-Birtill ${ }^{1}$
}

Published online: 14 February 2018

(C) The Author(s) 2018. This article is an open access publication

\begin{abstract}
Purpose of Review The present review was undertaken in order to summarize and evaluate recent research investigating taste exposure, sensory learning, and nutrition education interventions for promoting vegetable intake in preschool children.

Recent Findings Overall, taste exposure interventions yielded the best outcomes for increasing vegetable intake in early childhood. Evidence from sensory learning strategies such as visual exposure and experiential learning also show some success. While nutrition education remains the most common approach used in preschool settings, additional elements are needed to strengthen the educational program for increasing vegetable intake. There is a substantial gap in the evidence base to promote vegetable intake in food fussy children.

Summary The present review reveals the relative importance of different intervention strategies for promoting vegetable intake. To strengthen intervention effects for improving vegetable intake in preschool children, future research could consider integrating taste exposure and sensory learning strategies with nutrition education within the preschool curriculum.
\end{abstract}

Keywords Healthy eating intervention $\cdot$ Experiential learning $\cdot$ Taste exposure $\cdot$ Education intervention $\cdot$ Vegetable intake $\cdot$ Fussy eating

\section{Introduction}

\section{Developing Food Preferences Early Is Important}

Early childhood is a period of rapid growth and an important phase for developing eating habits because the dietary behaviors acquired during the early years of life can extend to adulthood [1-3]. Children learn about their food likes and dislikes by direct contact with foods, such as through tasting, feeling, seeing, and smelling, and also by observing their food environment, for example, the eating behaviors of others [4-6]. The significant rise in children with obesity by the time they start school is of public health concern [7]. In the UK, Health

This article is part of the Topical Collection on Psychological Issues

Chandani Nekitsing

c.nekitsing@leeds.ac.uk

Marion M. Hetherington

M.Hetherington@leeds.ac.uk

Pam Blundell-Birtill

P.Birtill@leeds.ac.uk

1 School of Psychology, University of Leeds, Leeds LS2 9JT, UK
Survey for England (HSE) 2014, has reported that 17\% of children aged 2-15 years are currently with obesity and a further $14 \%$ with overweight [8]. Similar figures are also reported in the USA; the 2013-2014 National Health and Nutrition Examination Survey indicated $17 \%$ children and adolescents aged 2-19 years with obesity, in addition to $16 \%$ with overweight [9].

Preventing excess adiposity includes increasing physical activity and matching dietary intake to energy requirements. Eating a well-balanced diet which is high in intake of fruits and vegetables (minimum $200 \mathrm{~g} /$ day for children and $400 \mathrm{~g} /$ day for adults) is thought to reduce the risk of obesity but also prevent various non-communicable diseases such as type 2 diabetes, cancers, and cardiovascular diseases $[10,11]$. Vegetables in particular are beneficial because they are low in naturally occurring sugars compared to fruits [12]. Studies with a largely middle-aged population indicated that eating vegetables confers a protective effect with each daily portion consumed reducing the probability of death by $16 \%$, compared to $4 \%$ for fruits [13]. Most children in the USA and UK eat far below the recommended amount of fruits and vegetables $[14,15]$ and increasing intake of vegetables remains challenging due to their bitter taste, texture, and low energy 
density. Also, eating behavior traits such as food fussiness and food neophobia can affect intake. Despite the various contributing factors for children's low consumption and dislike of many vegetables, the early years is a key period in development to encourage acceptance through appropriate behavioral techniques such as repeated taste exposure. The aim of the present review was to assess the relative importance of taste exposure, sensory learning, and nutrition education interventions to promote vegetable intake in preschool children; and to consider the ways in which vegetable intake and liking can be encouraged in fussy eaters.

\section{The Role of Food Fussiness and Food Neophobia}

Food fussiness is defined as selective food intake involving rejection of foods which are familiar as well as those which are unfamiliar, whereas food neophobia is specific to avoidance of new foods [16]. Food fussiness is typically measured using the Food Fussiness subscale of the Child Eating Behaviour Questionnaire [17] and food neophobia is often assessed using the Child Food Neophobia Scale [18]. These psychometric tools are reported to be reliable and valid; however, they tend to overlap in constructs which can be problematic when using them together. Both eating behaviors can have an adverse effect on healthy eating, since by selecting only preferred familiar foods, children may limit the quality and variety of their diet, especially by not eating sufficient vegetables [16, 19]. Food fussiness and food neophobia are highly correlated (with $r$ values around 0.7 ) and they both share common etiology in early childhood, which can be explained by heritability and shared environment factors, such as the home environment [20]. Food avoidance behaviors have been associated with low intake of fruits and vegetables $[19,21]$, and a recent study by Fildes et al. [22••] found that genes common to food fussiness also influence the intake of fruits and vegetables. It is understood that rejection of certain foods such as bitter vegetables and development of food avoidance behaviors are a consequence of natural evolutionary processes in which children's instinctive behavior is to avoid potentially harmful substances $[23,24]$. Nonetheless, it is important for children to include bitter, green leafy vegetables in the diet to promote health.

Food fussiness and food neophobia are known to peak between the ages 2 and 5 years; however, children in this age group are also open to acquiring new food preferences. Therefore, encouraging children using taste exposure and experiential learning strategies in a positive and supportive environment can promote familiarization and liking of unfamiliar foods, and over time, this may reduce their food avoidance behaviors $[2,25]$.

\section{Repeated Taste Exposure Interventions}

Studies of complementary feeding identify early flavor exposure to vegetables as an important strategy during the weaning stage (around 6 months) to encourage acceptance $[26,27]$. However, for some children, the taste and smell of some foods leads to a negative evaluation and hence to food refusal. Due to their bitter taste, this can be a particular problem when children eat vegetables. [28]. The socalled repeated taste exposure strategy ${ }^{1}$ in which children are offered the same foods frequently is reported to be the most effective way of promoting intake of unfamiliar vegetables in children [29••, 30-32]. The strategy works by a process of familiarization [33] and learned safety [34]. According to the mere exposure theory, a single exposure is sufficient to produce a positive attitude towards a stimulus; thus, repeated taste exposure interventions promote positive acceptance over time [33,35]. Studies have demonstrated that children increase their intake of vegetables after five exposures; however, on average, children will generally require between eight to ten exposures at a regular interval, e.g., once a week [31, 36-39]. The required number of exposures is often not achieved by the caregiver because they may interpret their child's facial expression as genuine dislike and therefore are unwilling to continue offering the same food [40-42].

A number of studies have been carried out using repeated taste exposures with other strategies such as non-food rewards (such as sticker or praise) $[38,43 \cdot, 44]$, modelling (learning by observing others, e.g., parents or peers) [38, 44], flavor-flavor learning (pairing with liked food or flavor, e.g., apple sauce or salt) $[32,45,46]$, and flavor-nutrient learning (added energy, e.g., oil) $[36,45]$. A study of reward and taste exposure by Fildes et al. [43.] found that parental administration of a single small piece of the disliked vegetables daily with a sticker was sufficient to increase the intake of a target vegetable in a home setting. Combining taste exposure with strategies such as rewards and modelling have long-lasting effects, up to 6 months post-intervention [44, 47]. However, Horne et al. [44] found that once liking for the target foods was established during snack time, the effects generalized to lunchtime in complete absence of reward. Most studies incorporating associative learning have found that mere exposure to the target vegetable alone is sufficient to increase the intake of the target vegetables, and adding flavors or nutrients provide no additional advantage [36, 45, 46, 48]. The exception to this observation was reported in a study showing that exposure alone was effective for a non-bitter familiar vegetable (cauliflower). However, adding cream cheese was more effective for

\footnotetext{
${ }^{1}$ It is understood that taste exposures involves more than just taste since children see, smell, and taste the food; however, many interventions refer to taste exposure rather than visual and flavor exposure.
} 
increasing liking of an unfamiliar bitter vegetable (Brussels sprouts) [49].

While the taste exposure strategy has a robust outcome for promoting vegetable intake in children, it should be noted that when a child tastes a food, taste is not the only sensory feature that they are exposed to. They also engage with the food using other non-taste sensory modalities such as hearing (the name of the food or sound it makes while chewing), sight (seeing the food), touch (feeling the texture in hands/ mouth), and smell of the food [24].

\section{Non-taste Sensory Learning Interventions: Sound, Sight, Touch, and Smell}

During complementary feeding, parents are advised to incorporate finger foods at mealtimes in order to encourage their children to experience new food textures. The hands-on learning which occurs during this time may facilitate acceptance of new and varied foods during this period. However, as children make the transition to the family diet, they move away from 'hands on' sensory exploration towards eating with spoon or fork and may be discouraged from 'playing with their food' at meal times.

Contemporary research with preschool children suggests that interventions could include non-taste sensory elements to familiarize children with fruits and vegetables [50••, 51, 52•]. Although their outcomes are not as favorable as taste exposure interventions, methods including listening, seeing, touching, and smelling may be very useful for young children, especially picky eaters as selective eating in preschool children has been associated with hypersensitivity to some of these senses [24, 52•, 53]. For example, food neophobic children and fussy eaters often reject vegetables based on their visual appearance or texture [16, 35, 52•, 54, 55]. Hence, interventions incorporating visual exposure including picture books and tactile-play activities may particularly benefit these children more than taste exposure alone.

\section{Visual Exposure and Narrative (Sound and Sight)}

Listening to stories and looking at pictures are activities which are regularly enjoyed by preschool children. Storybooks are generally engaging and interaction with the parent or caregiver during story time provides an opportunity for children to acquire new knowledge [56]. The illustrations in storybooks help children to better recall stories and being repeatedly exposed to pictures of foods increases children's visual familiarity with the foods $[57,58 \bullet]$. Research on visual exposure using picture books has had mixed results in terms of their effectiveness in increasing acceptance of vegetables [58 $\bullet$, 59-62]. For example, Heath et al. [58•] reported that toddlers aged 1926 months who were exposed to a storybook every day for 2 weeks consumed more of an unfamiliar vegetable that they had been visually exposed to compare to an unexposed control vegetable. The picture book exposure not only increased the intake of the unfamiliar vegetable, but it also reduced the level of encouragement needed for the children to taste the target foods. In comparison, de Droog et al. [62] reported a positive effect of exposure to a picture book (which included a narrative embedded with a health message) on intake of a familiar vegetable. They further added that picture books are particularly effective when the children are actively involved (e.g., when asked questions about the story). Children aged 4 6 years increased their intake of carrots more after being exposed to the vegetable in a picture book. The study also found that eating more carrots displaced consumption of cheese (high-calorie food). In contrast, a study with 4-8-year-old children found that engaging children with real vegetables produced a stronger effect on willingness to taste these vegetables (fresh soya bean) than visual exposure using photographs [51]. However, it should be noted that this study did not include a control group and perhaps visual exposure could increase willingness to taste relative to no exposure at all.

The main advantage of using this strategy is that it can be implemented outside of the meal context. This may alleviate the stress associated with tasting the vegetables for some children [24]. Other advantages of visual exposure using storybooks include ease of administration, social interaction between carers and children, engaging in a learning exercise to promote knowledge and awareness, and setting social norms. The many beneficial effects of visual exposure studies has given rise to research on multisensory learning for improving vegetable intake in children $[51,52 \bullet, 54,63-65]$.

\section{Role of Olfaction (Smell) in Food Intake}

Olfaction plays an important role in sensing of foods; the smell of the food contributes to overall flavor experience and can influence the desire to consume a particular food [66]. In adults who were restrained eaters, exposure to the odor of pizza increased intake, liking, and desire to eat that food [67]. In comparison, a study by Ramaekers et al. [68] with healthy-weight women reported that sniffing banana odor increased appetite for banana, although it did not influence the overall food intake. There are some inconsistences in findings reported from olfaction studies. However, the influence of odor on less palatable/less pungent foods such as raw vegetables is understudied and warrants further investigation. It should be noted that the outcome of olfactory activities may also depend on individual's awareness and ability to smell, both of which can vary by age $[69,70]$. Although there are no studies implementing olfactory experience alone for vegetable intake in children, there is emerging evidence for its use in multisensory interventions [24]. 


\section{Experiential Learning Intervention (Sound, Sight, Touch, and Smell)}

Sensory activities with food involving listening, seeing, smelling, touching, and tasting can be encouraged from a very young age (see Fig. 1 for simple techniques which can be used when introducing new foods to young children (ideas adapted from Dazeley et al. [24])). These learning strategies can be incorporated during the usual mealtimes or outside of the mealtime context, e.g., during cooking, gardening, and nutrition education sessions. For example, 'Taste for Life' is an intervention based on sensory learning which was developed to support nurseries in encouraging young children to eat healthily [71]. The program emphasizes having fun with fruits and vegetables outside of meal contexts, using different senses such as touch (handle, see, and smell), taste, and sound (song and rhyme time) $[50 \bullet \cdot$. However, it is not yet clear if this leads to changes in intake. Therefore, more research is needed to evaluate the effectiveness of existing programs, specifically how successful and feasible they are for improving vegetable intake.

Where studies have been conducted on multisensory learning (using sight, sound touch, smell, and excluding taste) as a way of familiarizing children to new foods, evidence suggests these are successful for increasing fruit and vegetable consumption. For example, a study in children aged 12-36 months found that familiarizing children to unfamiliar fruits and vegetables by looking, listening, feeling, and smelling them during playtime for 4 weeks increased their willingness to touch and taste these foods during lunch time [24]. Similarly,
Coulthard and Sealy [52•] found that a single session of sensory play with fruit and vegetables was enough to encourage children to try more of the study foods than those who only observed the fruit and vegetable sensory play session or received non-food sensory learning, demonstrating the importance of children actively touching and feeling the foods. However, this study only examined the effects on familiar vegetables (i.e., carrots, cucumber, and tomatoes [see, 72]), which may not generalize to unfamiliar vegetables.

Interacting with the sensory properties of food during tactileplay may particularly benefit children who are food neophobic, going through a period of fussy eating or who are simply unwilling to taste new/disliked foods $[50 \bullet \bullet, 52 \bullet, 54,65]$. However, these suggestions are only based on the correlations observed between food avoidance behaviors, sensory learning, and vegetable intake and therefore warrant further investigation. In particular, it should be noted that children who are picky/food fussy or neophobic may also be more sensitive to touch and therefore may dislike these types of activities.

\section{Nutrition Education Interventions}

Parents play a central role in their child's eating habits; however, as many young children regularly attend childcare, preschool settings are ideal for encouraging children to eat healthily [73•, 74]. In order to prevent obesity, public health interventions encourage preschool settings to promote healthy eating, in particular, to increase the consumption of fruits and vegetables. As a result of this, most day-care settings are required to integrate
Fig. 1 Basic sensory learning techniques that parents or preschool carers can use to encourage young children to become familiar with foods. Ideas adapted from work by Dazeley and Houston-Price [24]

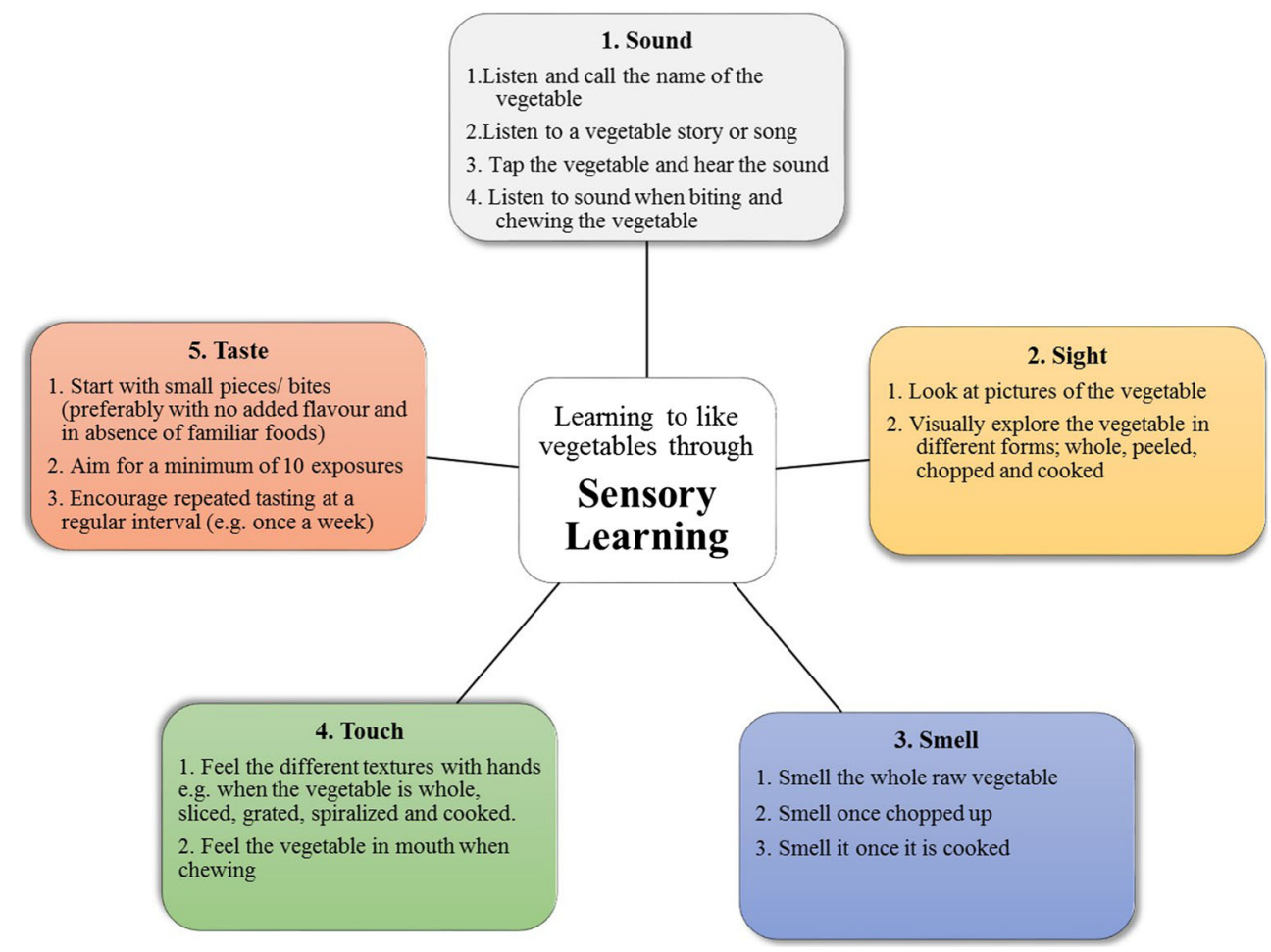


some nutrition education within the preschool curriculum [75]. Nutrition education programs in the early years' settings teach day-care staff, parents, and/or children about the nutritional value of food [76-78]. Interventions which involved parents generally involved giving them nutritional information. For example, Sharma et al. [79] sent a tip-sheet about modifying home nutrition, whereas Sirikulchayanonta et al. [80] provided a letter with guidance to motivate and encourage children to eat variety and quantity of fruits and vegetables, and Tabak et al. [81] gave parents the option to choose one of four newsletters from the following topics: vegetable availability, picky eating, modelling, or family meals. In education programs where children are involved, the sessions are usually interactive and engaging as they incorporate fun activities such as educational stories, drawing, games, gardening, cooking, and tasting [79, 82, 83].

Nutrition education programs vary in duration from a few weeks to several months, and they usually aim to increase consumption of familiar fruits and vegetables. While they are often successful in increasing vegetable intake in children, the effect sizes are smaller than other interventions such as sensory learning, reward, or taste exposure $[29 \bullet \bullet, 84,85 \bullet \cdot]$. One reason for the weaker outcomes may be the over-reliance on self-report (food frequency questionnaires) or assessing proxy measures of intake, such as liking, knowledge, and willingness to taste. More research with accurate intake data is needed, e.g., weighed intake in grams. Another reason why nutrition education may not be as effective as interventions involving hands-on experience is because children gain indirect experience through the curriculum rather than direct exposure to foods by smelling, feeling, and tasting. Therefore, incorporating sensory activities including taste to nutrition programs may provide an opportunity for children to improve both their knowledge and intake of vegetables.

\section{General Discussion and Future Research}

Evidence suggests that most published interventions that aim to improve vegetable intake are successful to some extent. However, they all have some limitations which should be considered when developing future interventions [85••]. Education is crucial for building knowledge about eating a variety of vegetables; however, simply learning about why and what we should eat does not bridge the gap between awareness and actual consumption. The effects of repeated taste exposure using a single vegetable are robust and durable. However, there is no evidence for its effect beyond the single target vegetable [86**]. Taste may be the most crucial sensory element when encouraging children to eat vegetables, but other sensory properties may be important as well. The emerging evidence from non-taste sensory learning is promising but the long-term impact of these strategies remains unknown [24]. Both taste exposure and non-taste sensory experience are more effective for increasing intake of unfamiliar vegetables compared to familiar vegetables. This may be a result of ceiling effects - it is difficult to increase the liking of vegetables that are already familiar and liked. Some generalization effects have been observed with taste exposure to a variety of vegetables [44] and this may also be relevant in future sensory interventions. More research is needed to understand if taste and experiential learning using a variety of vegetables can generalize to other vegetables and other settings (e.g., from preschool to home). Also, in order to sustain the change in intake of vegetables in the longer term, research could be conducted to investigate lasting effects of interventions.

It is often difficult to engage parents in nutrition education programs which are based in preschools. Therefore, there is a need for parental and preschool staff process evaluation which could help to build connections between providers and parents to improve children's nutrition [87]). A single strategy is unlikely to work for every child; therefore, combining strategies discussed earlier rather than using a single component intervention may benefit greater numbers of children, including those who are going through a period of picky eating. In particular, more research is needed to understand which strategies work for food fussy children.

\section{Conclusions}

Insufficient intake of vegetables in children remains an area of concern for parents and public health agencies. In order to improve children's nutrition, it is important that they eat the recommended quantity of vegetables. Repeated taste exposure strategies are the best evidenced for increasing intake of unfamiliar vegetables. However, there may be a role of experiential learning and nutrition education to expand the child's knowledge, awareness, and willingness to taste and also eat vegetables. Therefore, future research could identify the most effective elements of these strategies and integrate them to produce stronger and more durable outcomes for increasing vegetable intake in the early years.

Acknowledgments This article was kindly reviewed by Dr. Helen Coulthard (De Montfort University, Leicester, United Kingdom).

Funding This research is funded by ESRC Collaborative Award.

\section{Compliance with Ethical Standards}

Conflict of Interest Chandani Nekitsing, Marion M. Hetherington, and Pam Blundell-Birtill declare that they have no conflict of interest.

Human and Animal Rights and Informed Consent This article does not contain any studies with human or animal subjects performed by any of the authors. 
Open Access This article is distributed under the terms of the Creative Commons Attribution 4.0 International License (http:// creativecommons.org/licenses/by/4.0/), which permits unrestricted use, distribution, and reproduction in any medium, provided you give appropriate credit to the original author(s) and the source, provide a link to the Creative Commons license, and indicate if changes were made.

\section{References}

Papers of particular interest, published recently, have been highlighted as:

- Of importance

•- Of major importance

1. De Cosmi V, Scaglioni S, Agostoni C. Early taste experiences and later food choices. Nutrients. 2017;9(2):E107. https://doi.org/10. 3390/nu9020107.

2. Ventura Alison K, Worobey J. Early influences on the development of food preferences. Curr Biol. 2013;23(9):R401-R8. https://doi. org/10.1016/j.cub.2013.02.037.

3. Harris G. Development of taste and food preferences in children. Curr Opin Clin Nutr Metab Care. 2008;11(3):315-9. https://doi. org/10.1097/MCO.0b013e3282f9e228.

4. Nicklaus $\mathrm{S}$. The role of food experiences during early childhood in food pleasure learning. Appetite. 2016;104(Supplement C):3-9. https://doi.org/10.1016/j.appet.2015.08.022.

5. Sandell M, Mikkelsen BE, Lyytikäinen A, Ojansivu P, Hoppu U, Hillgrén A, et al. Future for food education of children. Futures. 2016;83(Supplement C):15-23. https://doi.org/10.1016/j.futures. 2016.04.006.

6. Johnson SL. Developmental and environmental influences on young children's vegetable preferences and consumption. Adv Nutr. 2016;7(1):220S-31S. https://doi.org/10.3945/an.115.008706.

7. de Onis M, Blossner M, Borghi E. Global prevalence and trends of overweight and obesity among preschool children. Am J Clin Nutr. 2010;92(5):1257-64. https://doi.org/10.3945/ajcn.2010.29786.

8. Health Survey for England 2014: Health, social care and lifestyles [Internet]. 2014. Available from: www.hscic.gov.uk/pubs/hse2014. Accessed 25 Oct 2017.

9. Fryar CD, Carroll MD, Ogden CL. Prevalence of overweight and obesity among children and adolescents aged 2-19 years: United States, 1963-1965 through 2013-2014. National Center for Health Statistics; 2016.

10. Aune D, Giovannucci E, Boffetta P, Fadnes LT, Keum N, Norat T, et al. Fruit and vegetable intake and the risk of cardiovascular disease, total cancer and all-cause mortality - a systematic review and dose-response meta-analysis of prospective studies. Int $\mathrm{J}$ Epidemiol. 2017;46(3):1029-56. https://doi.org/10.1093/ije/ dyw319.

11. World Health Organisation. Increasing fruit and vegetable consumption to reduce the risk of noncommunicable diseases. [Internet].2014. Available from: http://www.who.int/elena/titles/ fruit_vegetables_ncds/en/. Accessed 24.10.207.

12. Sharma SP, Chung HJ, Kim HJ, Hong ST. Paradoxical effects of fruit on obesity. Nutrients. 2016;8(10):633. https://doi.org/10.3390/ nu8100633.

13. Oyebode O, Gordon-Dseagu V, Walker A, Mindell JS. Fruit and vegetable consumption and all-cause, cancer and CVD mortality: analysis of health survey for England data. J Epidemiol Community Health. 2014;69(9):856-62. https://doi.org/10.1136/jech-2013203500 .
14. Center for Disease Control and Prevention. National Center for Chronic Disease Prevention and Health Promotion, Division of Nutrition, Physical Activity, and Obesity. Progress on children eating more fruit, not vegetables. [Internet]2015. Available from: https://www.cdc.gov/vitalsigns/fruit-vegetables/index.html. Accessed 17 Sep 2017.

15. Health Survey for England 2013, The Health and Social Care Information Center. Fruit and vegetable consumption, Chapter 7 [Internet] 2013. Available from: http://www.hscic.gov.uk/ catalogue/PUB16076/HSE2013-Ch7-fru-veg-com.pdf. Accessed 15.07.2016.

16. Dovey TM, Staples PA, Gibson EL, Halford JCG. Food neophobia and 'picky/fussy' eating in children: a review. Appetite. 2008;50(23):181-93. https://doi.org/10.1016/j.appet.2007.09.009.

17. Wardle J, Guthrie CA, Sanderson S, Rapoport L. Development of the children's eating behaviour questionnaire. J Child Psychol Psychiatry. 2001;42(7):963-70. https://doi.org/10.1111/14697610.00792

18. Pliner P. Development of measures of food neophobia in children. Appetite. 1994;23(2):147-63. https://doi.org/10.1006/ appe.1994.1043.

19. Cooke L, Carnell S, Wardle J. Food neophobia and mealtime food consumption in 4-5 year old children. Int J Behav Nutr Phys Act. 2006;3:14. https://doi.org/10.1186/1479-5868-3-14.

20. Smith AD, Herle M, Fildes A, Cooke L, Steinsbekk S, Llewellyn $\mathrm{CH}$. Food fussiness and food neophobia share a common etiology in early childhood. J Child Psychol Psychiatry. 2017;58(2):189-96. https://doi.org/10.1111/jcpp.12647.

21. Holley CE, Haycraft E, Farrow C. Predicting children's fussiness with vegetables: the role of feeding practices. Matern Child Nutr. 2017. https://doi.org/10.1111/mcn.12442.

22.• Fildes A, van Jaarsveld CHM, Cooke L, Wardle J, Llewellyn CH. Common genetic architecture underlying young children's food fussiness and liking for vegetables and fruit. Am J Clin Nutr. 2016;103(4):1099-104. https://doi.org/10.3945/ajcn.115.122945. This study highlighted the importance of genetic contribution to both food fussiness and liking for fruit and vegetable intake.

23. Rozin P, Vollmecke T. Food likes and dislikes. Annu Rev Nutr. 1986;6(1):433-56. https://doi.org/10.1146/annurev.nu.06.070186. 002245.

24. Dazeley P, Houston-Price C. Exposure to foods' non-taste sensory properties. A nursery intervention to increase children's willingness to try fruit and vegetables. Appetite. 2015;84:1-6. https://doi.org/ 10.1016/j.appet.2014.08.040.

25. Park B-K, Cho M-S. Taste education reduces food neophobia and increases willingness to try novel foods in school children. Nutr Res Pract. 2016;10(2):221-8. https://doi.org/10.4162/nrp. 2016.10.2.221.

26. Hetherington MM, Schwartz C, Madrelle J, Croden F, Nekitsing C, Vereijken CMJL, et al. A step-by-step introduction to vegetables at the beginning of complementary feeding. The effects of early and repeated exposure. Appetite. 2015;84(Supplement C):280-90. https://doi.org/10.1016/j.appet.2014.10.014.

27. Barends C, de Vries J, Mojet J, de Graaf C. Effects of repeated exposure to either vegetables or fruits on infant's vegetable and fruit acceptance at the beginning of weaning. Food Qual Prefer. 2013;29(2):157-65. https://doi.org/10.1016/j.foodqual.2013. 03.008 .

28. Gibson EL, Wardle J, Watts CJ. Fruit and vegetable consumption, nutritional knowledge and beliefs in mothers and children. Appetite. 1998;31(2):205-28. https://doi.org/10.1006/appe. 1998.0180

29.• Holley CE, Farrow C, Haycraft E. A systematic review of methods for increasing vegetable consumption in early childhood. Curr Nutr Rep. 2017;6(2):157-70. https://doi.org/10.1007/s13668-017-02021. A very recent systematic review highlighting interventions 
important for increasing consumption of fruit and vegetables in preschool children aged $2-5$ years.

30. Caton SJ, Blundell P, Ahern SM, Nekitsing C, Olsen A, Møller P, et al. Learning to eat vegetables in early life: the role of timing, age and individual eating traits. PLoS One. 2014;9(5):e97609. https:// doi.org/10.1371/journal.pone.0097609.

31. Hausner H, Olsen A, Moller P. Mere exposure and flavour-flavour learning increase 2-3 year-old children's acceptance of a novel vegetable. Appetite. 2012;58(3):1152-9. https://doi.org/10.1016/j. appet.2012.03.009.

32. Ahern SM, Caton SJ, Blundell P, Hetherington MM. The root of the problem: increasing root vegetable intake in preschool children by repeated exposure and flavour flavour learning. Appetite. 2014;80: 154-60. https://doi.org/10.1016/j.appet.2014.04.016.

33. Zanjonc RB. Attitudinal effects of mere exposure. J Pers Soc Psychol Monogr. 1968;9(2 Pt. 2):1-27.

34. Kalat JW, Rozin P. "Learned safety" as a mechanism in long-delay taste-aversion learning in rats. J Comp Physiol Psychol. 1973;83(2):198-207. https://doi.org/10.1037/h0034424.

35. Rioux C, Lafraire J, Picard D. Visual exposure and categorization performance positively influence 3- to 6-year-old children's willingness to taste unfamiliar vegetables. Appetite. 2018;120(Supplement C):32-42. https://doi.org/10.1016/j.appet. 2017.08.016.

36. Caton SJ, Ahern SM, Remy E, Nicklaus S, Blundell P, Hetherington MM. Repetition counts: repeated exposure increases intake of a novel vegetable in UK pre-school children compared to flavour-flavour and flavour-nutrient learning. Br J Nutr. 2013;109(11):2089-97. https://doi.org/10.1017/ S0007114512004126.

37. de Wild VWT, de Graaf C, Jager G. Use of different vegetable products to increase preschool-aged children's preference for and intake of a target vegetable: a randomized controlled trial. J Acad Nutr Diet. 2017;117(6):859-66. https://doi.org/10.1016/j.jand. 2016.11.006.

38. Remington A, Aññez E, Croker H, Wardle J, Cooke L. Increasing food acceptance in the home setting: a randomized controlled trial of parent-administered taste exposure with incentives. Am J Clin Nutr. 2012;95(1):72-7. https://doi.org/10.3945/ajcn.111.024596.

39. Birch LL, McPhee L, Shoba BC, Pirok E, Steinberg L. What kind of exposure reduces children's food neophobia? Looking vs. tasting. Appetite. 1987;9(3):171-8.

40. Cooke LJ, Wardle J, Gibson EL, Sapochnik M, Sheiham A, Lawson M. Demographic, familial and trait predictors of fruit and vegetable consumption by pre-school children. Public Health Nutr. 2004;7(2):295-302.

41. Cooke LJ, Haworth CM, Wardle J. Genetic and environmental influences on children's food neophobia. Am J Clin Nutr. 2007;86(2): 428-33.

42. Carruth BR, Ziegler PJ, Gordon A, Barr SI. Prevalence of picky eaters among infants and toddlers and their caregivers' decisions about offering a new food. J Am Diet Assoc. 2004;104(1 Suppl 1): s57-64. https://doi.org/10.1016/j.jada.2003.10.024.

43. Fildes A, van Jaarsveld CHM, Wardle J, Cooke L. Parentadministered exposure to increase children's vegetable acceptance: a randomized controlled trial. J Acad Nutr Diet. 2014;114(6):8818. https://doi.org/10.1016/j.jand.2013.07.040. An important study looking at taste exposure intervention in to increase vegetable intake in home setting.

44. Horne PJ, Greenhalgh J, Erjavec M, Lowe C, Viktor S, Whitaker CJ. Increasing pre-school children's consumption of fruit and vegetables. A modelling and rewards intervention. Appetite. 2011;56(2):375-85. https://doi.org/10.1016/j.appet.2010.11.146.

45. de Wild VWT, de Graaf C, Jager G. Effectiveness of flavour nutrient learning and mere exposure as mechanisms to increase toddler's intake and preference for green vegetables. Appetite. 2013;64:8996. https://doi.org/10.1016/j.appet.2013.01.006.

46. Ahern SM, Caton SJ, Blundell P, Hetherington MM. Increasing pre-school children's liking for a novel vegetable. A comparison of flavour flavour learning and repeated exposure. Appetite. 2013;71(Supplement C):470. https://doi.org/10.1016/j.appet.2013. 06.008 .

47. Cooke LJ, Chambers LC, Añez EV, Croker HA, Boniface D, Yeomans MR, et al. Eating for pleasure or profit: the effect of incentives on children's enjoyment of vegetables. Psychol Sci. 2011;22(2):190-6. https://doi.org/10.1177/0956797610394662.

48. Bouhlal S, Issanchou S, Chabanet C, Nicklaus S. 'Just a pinch of salt'. An experimental comparison of the effect of repeated exposure and flavor-flavor learning with salt or spice on vegetable acceptance in toddlers. Appetite. 2014;83:209-17. https://doi.org/10. 1016/j.appet.2014.07.032.

49. Capaldi-Phillips ED, Wadhera D. Associative conditioning can increase liking for and consumption of brussels sprouts in children aged 3 to 5 years. J Acad Nutr Diet. 2014;114(8):1236-41. https:// doi.org/10.1016/j.jand.2013.11.014.

50.• Dazeley P, Houston-Price C, Hill C. Should healthy eating programmes incorporate interaction with foods in different sensory modalities? A review of the evidence. Br J Nutr. 2012;108(5):769 77. https://doi.org/10.1017/S0007114511007343. This review is very important for highlighting the importance of multisensory interactions with foods to increase consumption of fruit and vegetables.

51. Coulthard H, Ahmed S. Non taste exposure techniques to increase fruit and vegetable acceptance in children: effects of task and stimulus type. Food Qual Prefer. 2017;61(Supplement C):50-4. https:// doi.org/10.1016/j.foodqual.2017.04.012.

52. Coulthard H, Sealy A. Play with your food! Sensory play is associated with tasting of fruits and vegetables in preschool children. Appetite. 2017;113:84-90. https://doi.org/10.1016/j.appet.2017. 02.003. This is one of the most recent studies looking at sensory play activities using fruits and vegetables to encourage fruit and vegetable tasting in preschool children.

53. Zucker N, Copeland W, Franz L, Carpenter K, Keeling L, Angold A, et al. Psychological and psychosocial impairment in preschoolers with selective eating. Pediatrics. 2015;136(3):e582-90. https://doi.org/10.1542/peds.2014-2386.

54. Coulthard H, Thakker D. Enjoyment of tactile play is associated with lower food neophobia in preschool children. J Acad Nutr Diet. 2015;115(7):1134-40. https://doi.org/10.1016/j.jand.2015.02.020.

55. van der Horst K, Deming DM, Lesniauskas R, Carr BT, Reidy KC. Picky eating: associations with child eating characteristics and food intake. Appetite. 2016;103(Supplement C):286-93. https://doi.org/ 10.1016/j.appet.2016.04.027.

56. Horst JS, Houston-Price C. Editorial: an open book: what and how young children learn from picture and story books. Front Psychol 2015;6(1719). https://doi.org/10.3389/fpsyg.2015.01719

57. Greenhoot AF, Beyer AM, Curtis J. More than pretty pictures? How illustrations affect parent-child story reading and children's story recall. Front Psychol. 2014;5:738. https://doi.org/10.3389/fpsyg. 2014.00738.

58. Heath P, Houston-Price C, Kennedy OB. Let's look at leeks! Picture books increase toddlers' willingness to look at, taste and consume unfamiliar vegetables. Front Psychol. 2014;5:191. https://doi.org/ 10.3389/fpsyg.2014.00191. An important study looking at visual exposure in home setting to increase vegetable consumption.

59. Heath $\mathrm{P}$, Houston-Price $\mathrm{C}, \mathrm{Kennedy} \mathrm{OB}$. Increasing food familiarity without the tears. A role for visual exposure? Appetite. 2011;57(3): 832-8. https://doi.org/10.1016/j.appet.2011.05.315.

60. Houston-Price C, Butler L, Shiba P. Visual exposure impacts on toddlers' willingness to taste fruits and vegetables. Appetite. 2009;53(3):450-3. https://doi.org/10.1016/j.appet.2009.08.012. 
61. Osborne CL, Forestell CA. Increasing children's consumption of fruit and vegetables: does the type of exposure matter? Physiol Behav. 2012;106(3):362-8. https://doi.org/10.1016/j.physbeh. 2012.01.006.

62. de Droog SM, Buijzen M, Valkenburg PM. Enhancing children's vegetable consumption using vegetable-promoting picture books. The impact of interactive shared reading and character-product congruence. Appetite. 2014;73(Supplement C):73-80. https://doi. org/10.1016/j.appet.2013.10.018.

63. Coulthard H, Palfreyman Z, Morizet D. Sensory evaluation of a novel vegetable in school age children. Appetite. 2016;100(Supplement C):64-9. https://doi.org/10.1016/j.appet. 2016.01.030.

64. Coulthard H, Williamson I, Palfreyman Z, Lyttle S. Evaluation of a pilot sensory play intervention to increase fruit acceptance in preschool children. Appetite. 2017. https://doi.org/10.1016/j.appet. 2017.10.011

65. Nederkoorn C, Jansen A, Havermans RC. Feel your food. The influence of tactile sensitivity on picky eating in children. Appetite. 2015;84:7-10. https://doi.org/10.1016/j.appet.2014. 09.014.

66. Boesveldt $\mathrm{S}$, de Graaf K. The differential role of smell and taste for eating behavior. Perception. 2017;46(3-4):307-19. https://doi.org/ 10.1177/0301006616685576.

67. Fedoroff I, Polivy J, Herman CP. The specificity of restrained versus unrestrained eaters' responses to food cues: general desire to eat, or craving for the cued food? Appetite. 2003;41(1):7-13.

68. Ramaekers MG, Boesveldt S, Gort G, Lakemond CM, van Boekel MA, Luning PA. Sensory-specific appetite is affected by actively smelled food odors and remains stable over time in normal-weight women. J Nutr. 2014;144(8):1314-9. https://doi.org/10.3945/jn. 114.192567.

69. Monnery-Patris S, Wagner S, Rigal N, Schwartz C, Chabanet C, Issanchou $\mathrm{S}$, et al. Smell differential reactivity, but not taste differential reactivity, is related to food neophobia in toddlers. Appetite. 2015;95:303-9. https://doi.org/10.1016/j.appet.2015.07.021.

70. Wagner S, Issanchou S, Chabanet C, Lange C, Schaal B, Monnery-Patris S. Liking the odour, liking the food. Toddlers' liking of strongly flavoured foods correlates with liking of their odour. Appetite. 2014;81:60-6. https://doi.org/ 10.1016/j.appet.2014.06.002.

71. Organix. Taste for Life. A fun pre-school education programme. [Internet]. Available from: http://www.organix.nl/sites/default/ files/activity_sheets/leaders-pack.pdf. Accessed 28 Oct 2017.

72. Ahern SM, Caton SJ, Bouhlal S, Hausner H, Olsen A, Nicklaus S, et al. Eating a rainbow. Introducing vegetables in the first years of life in 3 European countries. Appetite. 2013;71(Supplement C):48 56. https://doi.org/10.1016/j.appet.2013.07.005.

73. Mikkelsen MV, Husby S, Skov LR, Perez-Cueto FJ. A systematic review of types of healthy eating interventions in preschools. Nutr J. 2014;13:56. https://doi.org/10.1186/1475-2891-13-56. Important systematic review highlighting equational interventions in preschools to promote healthy eating.

74. Kobel S, Wartha O, Wirt T, Dreyhaupt J, Lammle C, Friedemann E$\mathrm{M}$, et al. Design, implementation, and study protocol of a kindergarten-based health promotion intervention. Biomed Res Int. 2017;2017:9. https://doi.org/10.1155/2017/4347675.
75. Department For Education. Statutory framework for the early years foundation stage [Internet]2017. Available from: https://www. foundationyears.org.uk/files/2017/03/EYFS STATUTORY FRAMEWORK_2017.pdf. Accessed 02 Nov 2017.

76. Bell LK, Hendrie GA, Hartley J, Golley RK. Impact of a nutrition award scheme on the food and nutrient intakes of 2- to 4-year-olds attending long day care. Public Health Nutr. 2015;18(14):2634-42. https://doi.org/10.1017/S1368980014003127.

77. Williams PA, Cates SC, Blitstein JL, Hersey J, Gabor V, Ball M, et al. Nutrition-education program improves preschoolers' at-home diet: a group randomized trial. J Acad Nutr Diet. 2014;114(7): 1001-8. https://doi.org/10.1016/j.jand.2014.01.015.

78. Gripshover SJ, Markman EM. Teaching young children a theory of nutrition: conceptual change and the potential for increased vegetable consumption. Psychol Sci. 2013;24(8):1541-53. https://doi.org/ 10.1177/0956797612474827.

79. Sharma S, Chuang R-J, Hedberg AM. Pilot-testing CATCH early childhood: a preschool-based healthy nutrition and physical activity program. Am J Clin Nutr. 2011;42(1):12-23. https://doi.org/10. 1080/19325037.2011.10599169.

80. Sirikulchayanonta C, Iedsee K, Shuaytong P, Srisorrachatr S. Using food experience, multimedia and role models for promoting fruit and vegetable consumption in Bangkok kindergarten children. Nutr Diet. 2010;67(2):97-101. https://doi.org/10.1111/j.1747-0080. 2010.01426.x

81. Tabak RG, Tate DF, Stevens J, Siega-Riz AM, Ward DS. Family ties to health program: a randomized intervention to improve vegetable intake in children. J Nutr Educ Behav. 2012;44(2):166-71. https://doi.org/10.1016/j.jneb.2011.06.009.

82. Witt KE, Dunn C. Increasing fruit and vegetable consumption among preschoolers: evaluation of "Color Me Healthy". J Nutr Educ Behav. 2012;44(2):107-13. https://doi.org/10.1016/j.jneb. 2011.01.002.

83. Vereecken C, Huybrechts I, Houte H, Martens V, Wittebroodt I, Maes L. Results from a dietary intervention study in preschools "Beastly Healthy at School". Int J Public Health. 2009;54(3):142_ 9. https://doi.org/10.1007/s00038-009-8028-2

84. DeCosta P, Moller P, Frost MB, Olsen A. Changing children's eating behaviour - a review of experimental research. Appetite. 2017;113:327-57. https://doi.org/10.1016/j.appet.2017.03.004.

85.• Appleton KM, Hemingway A, Saulais L, Dinnella C, Monteleone E, Depezay L, et al. Increasing vegetable intakes: rationale and systematic review of published interventions. Eur J Nutr. 2016;55(3):869-96. https://doi.org/10.1007/s00394-015-1130-8. This systematic review includes range of vegetable interventions through lifespan. Detailing overall which strategies are important for increasing vegetable intake.

$86 . \bullet$ Hendrie GA, Lease HJ, Bowen J, Baird DL, Cox DN. Strategies to increase children's vegetable intake in home and community settings: a systematic review of literature. Matern Child Nutr. 2016;13(1):e12276. https://doi.org/10.1111/mcn.12276. This systematic review is very important for highlighting interventions which are successful for increasing consumption of fruit and vegetables in children.

87. Dev DA, Byrd-Williams C, Ramsay S, McBride B, Srivastava D, Murriel A, et al. Engaging parents to promote children's nutrition and health. Am J Health Promot. 2017;31(2):153-62. https://doi. org/10.1177/0890117116685426. 